http://jaet.journals.ekb.eg

\title{
PERFORMANCE EVALUATION OF UTILIZING M-QAM OFDM WITH SC- LPPM FOR INDOOR LOS-VLC SYSTEMS
}

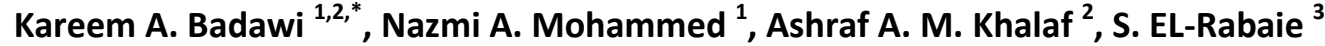 \\ ${ }^{I}$ Photonic Research Lab, Electrical Engineering Department, College of Engineering, Dawadmi, Shaqra \\ University, Kingdom of Saudi Arabia, 11961. OSA Member. \\ ${ }^{2}$ Faculty of Engineering, Minia University, Minia, Egypt, P.O. Box61111, Minia, Egypt. \\ ${ }^{3}$ Dept. of Electronics and Communication Eng., Faculty of Electronic Eng., Menoufia University. \\ *Corresponding author E-mail: kareem.badawi@hotmail.com
}

\begin{abstract}
In this paper, a combination process for sub-carrier pulse modulation (SC- LPPM) technique with Mary Quadrature Amplitude Modulation OFDM (M-QAM OFDM) under distinctive and uniform lighting topologies assumption in a typical room is introduced. It was indicated from previous literatures that SCLPPM fails to achieve the minimum performance required to achieve and sustain a reliable communication link; hence, it can be predicted that utilizing optical OFDM techniques can enhance the scheme performance allowing it to sustain a reliable communication link performance while achieving a higher operating data rate with an acceptable BER performance. However, the presented study can be more informative if the investigation is carried for different room and lighting topologies which will indicate the capabilities and the limitations of the proposed combination scheme. It can be shown in the manuscript that under distinctive lighting topology assumption, utilizing M-QAM OFDM with a single carrier modulation technique (SCM) like SC- LPPM can enhance the operating bit rate performance up to $50 \mathrm{Mbps}$ with a remarkable BER performance of $8.6 \times 10^{-5}$ at modulation level $(\mathrm{L}=8)$, which can maintain a reliable communication link for Visible Light Communication (VLC) systems. Meanwhile, further improvement to the BER performance up to $9.56 \times 10^{-6}$ can be achieved for the same modulation level at a $5 \mathrm{Mbps}$ rate. Moreover, an investigation for the power performance of the proposed technique, the minimum required power, and the power distribution across the presented rooms topologies is presented in the manuscript under two scenarios (i.e., with and without utilizing SC- LPPM with M-QAM OFDM), which will help identifying the most suitable room and lighting layout to utilize the proposed scheme and give an insight into the performance enhancement that occurred due to the utilization of optical OFDM.
\end{abstract}

\section{Keywords: Visible light communication, Sub-carrier pulse position modulation, Multi-carrier} modulation, Bit error rate, M-QAM OFDM.

\section{INTRODUCTION}

Light Fidelity (Li-Fi) is the commercial acronym for Visible Light Communication (VLC) which had gained huge attention in the research and development globally as an alternative to Radio Frequency (RF) technology [1-5]. VLC unlike RF provides multiple advantages like unlicensed bandwidth, infrastructure availability, lack of interference with both surrounding electronics and RF circuits, enhanced privacy, and high security [6].

Received:29 March 2021, Accepted:28 April , 2021
Moreover, Li-Fi had become a state-of-theart optical communication technology. It can be considered as an advanced version of free-space optical communication (FSO) especially for indoor environments [7]. Several optoelectronic/ photonic devices/platforms such as Mach Zehnder Interferometer (MZI), Fiber Bragg grating (FBG), and semiconductor optical amplifiers (SOAs), began to focus and switch some of their applications to keep up with the noticeable widespread of Li-Fi technology especially in indoor optical communication environments [8 - 13]. 
Although photonic crystals and other all-optical devices shows a promising integration ability and a remarkable power consumption performance, they suffer from complex system and structure designs compared to VLC technology [13 - 17].

VLC technology uses light as a method of communication, unlike conventional illumination devices, LEDs provide many advantages like durability, enhanced robustness, high switching rate, and smaller sizes which leads to the conclusion that LEDs can be more efficient in VLC systems [18, 21, 22].

VLC has many applications which includes high data rate transmission, underwater communications and transmission in sensitive electromagnetic interference environments, also it can be utilized in the traffic control systems to enable, control, and automate the infrastructure-to-vehicle communication $[23,24,25]$.

Another advantage of VLC is the power consumption enhancement to provide communication while maintaining the required lighting and illumination strength, thus, the two major purposes of LED-based systems are the efficient accomplishment of both dimming and communication support.

Dimming and communication can be fulfilled by different modulation techniques [21], dimming support can be accomplished using Pulse Width Modulation (PWM) and Pulse Amplitude Modulation (PAM). Meanwhile, data transmission (i.e., communication) can be accomplished using On-Off Keying (OOK) and Pulse Position Modulation (PPM) [27]. Despite the power consumption penalty of OOK based techniques, these techniques are considered as straight forward, simply designed and known as Single-Carrier Modulation (SCM) techniques. However, some of these techniques lacks the required illumination capabilities required for $\mathrm{Li}-\mathrm{Fi}$ enabled systems (i.e., dimming support while maintaining a reliable communication link).

To achieve both bandwidth and power efficiency, SCM techniques like PPM and its variants, such as Inverted L-ary Pulse Position Modulation (I-LPPM), L-ary Pulse Position Modulation (LPPM), and MultiPulse PPM (MPPM) are considered as effective techniques [28].

However, these techniques are not the most effective techniques that can be utilized as VLC modulation techniques, since most of these modulation techniques are designed for free-space-optical communication utilizing infrared (IR) transmission which can only support data transmission (i.e., communication support). Hence, it can be assumed that these techniques did not support dimming.

Moreover, techniques suffer from the effect of Inter Symbol Interference (ISI), and their performance decreases at high data rates. leading to the introduction of several equalization techniques that can be used as a reliable method to enhance the system performance at high data rates [29 31].

Although, utilizing these techniques with SCM shows a noticeable enhancement in the system performance but the system design complexity was very high due to the dispersive nature of the optical channel that leads to a noticeable decrease in their spectral efficiency. Hence, utilizing MultiCarrier Modulation (MCM) techniques such as Orthogonal Frequency Division Multiplexing (OFDM) was introduced as a reliable substitute for these equalization techniques for Li-Fi systems [32].

In [33], Z. Wang presented a technique that applies dimming control to a scheme that combines OFDM with Multi levelQuadrature Amplitude Modulation (MQAM). A modification to this scheme is presented in [34] that can achieve excess data transmission by merging Multi PulsePosition Modulation (MPPM) pulses with M-QAM OFDM. The excess transmitted information will result in reducing the required data rate to achieve a reliable communication link, which leads to enhancing the overall power consumption and complexity. 
In [20], the authors focused on reducing the total power consumption of the LED while achieving both lighting and communication requirements.

SC-LPPM technique performance was investigated in [35] as a power efficient SCM technique, it was shown in [35] that SC-LPPM can sustain a reliable illumination performance and a power saving performance while achieving a remarkable BER performance at lower operating data rates (i.e., up to $3 \mathrm{Mbps}$ ). Also, it can be indicated that the presented investigation was limited to only $15 \mathrm{Mbps}$ under a distinctive lighting topology assumption which fails to present the scheme's performance at higher operating data rates.

Another study was presented in [36] to investigate the effect of different system and environmental parameters on the scheme performance under Non-Line of Sight (NLOS) link assumption for distinctive lighting topology. But the study showed that the NLOS component can enhance the system power, BER, and illumination performance for the same operating data rates as [35].

It can be concluded from $[35,36]$ that, although SC- LPPM showed a remarkable performance as a power-saving modulation technique with a remarkable illumination performance, it has several operation limitations due to its lack of endurance against the effect of ISI.

Hence, it can be predicted that SCLPPM can show an improvement in its overall performance as a reliable powersaving VLC technique if combined with MQAM OFDM, especially at higher operating data rates.

In [37] several SCM techniques are combined with M-QAM OFDM under distinctive and uniform lighting topologies assumption and investigated as a reliable dimming control scheme for VLC based systems, which showed the remarkable capabilities of SC-LPPM as power saving technique, that can sustain a reliable illumination performance.
But the work presented in [37] assumed a BER of $10^{-3}$ and failed to present the BER performance of the scheme at higher operating data rates along with the power distribution performance across the proposed room and lighting topology.

It can be indicated that previous literature investigated the combination process of SCM techniques with M-QAM OFDM, assumed a BER performance of $10^{-3}$ to produce their analysis, which does not reflect the capabilities of the proposed technique as Li-Fi enabled scheme that can support a reliable communication link at increased operating data rates [33, 34, 37].

Moreover, literatures investigated the BER, power, and illumination performance of SC- LPPM scheme under low data rates assumption (i.e., up to $15 \mathrm{Mbps}$ ) due to the low BER performance of the scheme at higher data rates reflects to the power requirements and the overall performance of the scheme in a noticeable way, which will result in increased power consumption.

Hence, it can be predicted that utilizing optical OFDM techniques can enhance the scheme performance allowing it to sustain a reliable communication link performance while achieving a higher operating data rate with an acceptable BER performance.

In this work, the BER performance of SC-LPPM scheme is investigated at higher operating data rates (i.e., up to $50 \mathrm{Mbps}$ ), as a SCM modulation scheme and after being combined M-QAM OFDM for a line of sight (LOS) environment under distinctive and uniform lighting topologies assumption.

Which represents an insight into the scheme performance and determine the capabilities and the limitations of the scheme as reliable VLC scheme that can sustain a reliable communication link in both lighting topologies. Followed by an analysis for the minimum required power, $\left(P_{\text {req. }}\right)$ to investigate the performance enhancement of utilizing OFDM with SCLPPM for the two proposed rooms topologies. 
Another side of this study is to analyze the performance and stability of the system across the presented rooms layout (i.e., Under the light source and the room corners). This analysis can help investigating the operation system rate limitations of the presented technique as a reliable VLC system.

The rest of this paper is organized as follows, Section 2 describes the system environment, where the channel model will be presented in section 3 , section 4 holds the presented system design and rooms topologies parameters, in section 5 the obtained results will be presented and discussed. Section 6 presents a survey on different modulation techniques utilized by different literatures. Finally, section 7 will hold the main conclusion of the manuscript.

\section{SYSTEM MODEL}

The presented distinctive room topology consists of four identical LED sources that are equally placed and spaced on the room ceiling of a $\left(5 \times 5 \times 3 \mathrm{~m}^{3}\right)$ room at a center position of $(1.25,1.25,2.5)$, $(1.25,3.75,2.5),(3.75,1.25,2.5),(3.75$, $3.75,2.5)$. Meanwhile, the receiver is assumed to be at desk level of height $(0.85$ $\mathrm{m})$, as shown in Fig. 1(a).

A $20 \times 25$ LED chip triangular array is assumed for the uniform lighting topology. The LED chips are distributed of the ceiling of the proposed room in an equilateral triangle with side length of 0.24 $\mathrm{m}$, as shown in Fig. 1(b).

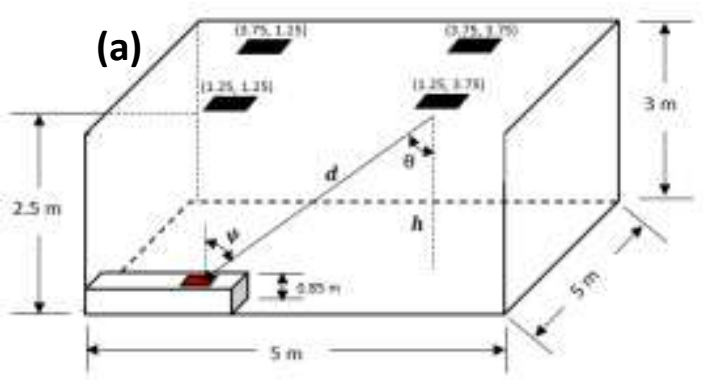

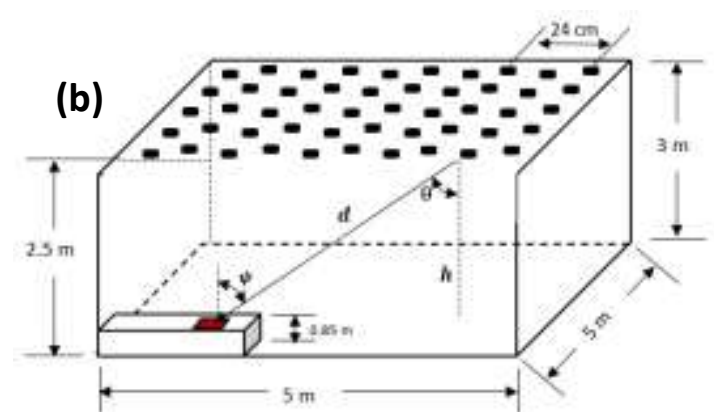

Fig. 1. Room configuration for (a) distinctive lighting layout, (b) uniform lighting layout.

To construct an SC- LPPM symbol, a direct current component and a subcarrier component (SC) are required. Where the symbol interval (T) can be formed by $L$ equal time slots. Moreover, it can be indicated that only one of these $L$ slots carries the optical signal, while a constant current amplitude is carried by the rest of the symbol interval $(L-1)$. Fig. 2 demonstrates the waveform of an SC-4 PPM symbol. where $\mathrm{c}$ is the maximum value of the optical signal, $a$ is the minimum value of the optical signal, $(c-a)$ represents the amplitude of the optical signal [26], and (b) represents the amplitude of the DC component [35].

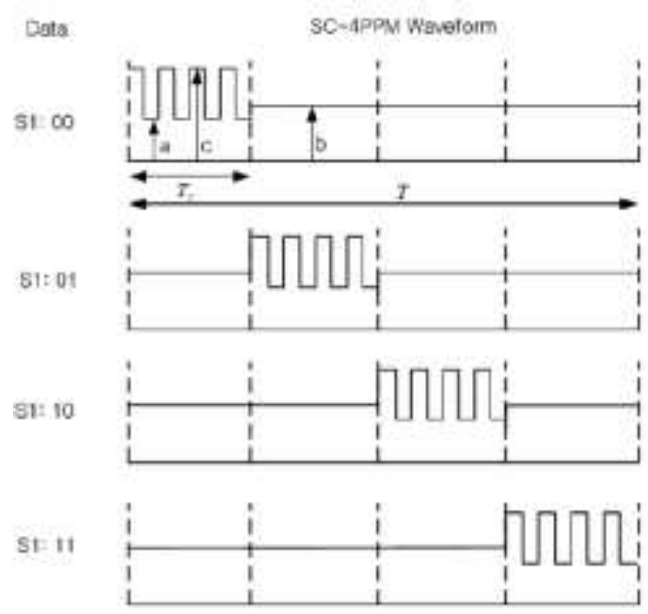

Fig. 2. SC-4 PPM waveform $[21,35]$.

\section{CHANNEL MODEL}

The signal intensity in optical communication is controlled by the transmitted optical power radiated by the LED [21]. To evaluate the transmitted optical signal strength of an SC- LPPM symbol, only the transmitted power through the subcarrier component is accounted for, 
thus it can be described as follows

$$
P_{i}^{t}=(c-a) \times P_{\max }^{t}
$$

where $P_{i}^{t}$ is the optical transmitted power from $i^{\text {th }}$ LED source, $P_{\max }^{t}$ is the maximum optical power transmitted by the $i^{\text {th }}$ LED source, and $(c-a)$ is the amplitude of the optical signal.

For an optical wireless channel, the power received by a photodiode (PD) can be acquired from [21]

$$
\mathrm{P}_{\mathrm{j}}^{\mathrm{r}}=\sum_{\mathrm{i}=1}^{\mathrm{I}}\left(\mathrm{H}(0) \times \mathrm{P}_{\mathrm{i}}^{\mathrm{t}}\right)
$$

where $P_{j}^{r}$ is the optical power received at the receiving location $j$ across the room from the LED sources, and $H(0)$ is the channel response, which can be presented as follows [36, 37]

$$
\mathrm{H}(0)=\frac{A_{\mathrm{PDr}}(\mathrm{m}+1)}{2 \pi \mathrm{d}_{\mathrm{o}}^{2}} \mathrm{~T}(\theta) \mathrm{g}(\theta) \cos ^{m}(\theta) \cos \psi
$$

where $A_{P D r}$ is the effective area of the PD, $T(\theta)$ is the optical filter gain, and $g(\theta)$ is the concentrator gain.

Hence, from Eq. (1), (2), and (3), the total received optical power can be represented as follows

$$
\begin{aligned}
& \begin{array}{l}
\mathrm{P}_{1}^{\mathrm{r}}= \\
\left\{\left(\mathrm{c}_{\mathrm{i}}-\mathrm{a}_{\mathrm{i}}\right) \times \mathrm{P}_{\max }^{\mathrm{t}} \times \frac{A_{\mathrm{PDr}}(\mathrm{m}+\mathcal{1})}{2 \pi \mathrm{d}_{\mathrm{N}}^{\mathrm{N}}} \mathrm{T}(\theta) \mathrm{g}(\theta) \cos ^{\mathrm{m}}(\theta) \cos \psi, \theta \leq \mathrm{FOV}\right.
\end{array} \\
& 0, \theta>\text { FOV }
\end{aligned}
$$

where FOV is the receiver Field of View.

The BER is the lead parameter that can be used to assess the performance of a communication system, for SC-LPPM, it can be acquired from [21]

$$
\left.\mathrm{BER}\right|_{\mathrm{SCM}}=\frac{\mathrm{L} / 2}{\mathrm{~L}-1} \mathrm{Q}\left(\frac{1}{2} \sqrt{\frac{3 \mathrm{~A}_{\mathrm{PDr}}^{2} \mathrm{~L}\left(\mathrm{P}_{\mathrm{F}}^{\mathrm{F}}\right)^{2} \log _{2} \mathrm{~L}}{\mathrm{~N}_{\mathrm{o}} \mathrm{R}_{\mathrm{b}}}}\right)
$$

where $R_{b}$ is the bit rate, and $N_{o}$ is the power spectral density of additive white Gaussian noise channel.

The received optical power $P_{j}^{r}$ should be greater than or equal to the minimum power required, $P_{\text {req }}$. for SC-PPM to accomplish a given BER which is stated in [21]

$$
\mathrm{P}_{\text {req }}=\frac{2}{\mathrm{~A}_{\mathrm{PDr}}} \mathrm{Q}^{-1}\left(\left(\frac{\mathrm{L}-1}{\mathrm{~L} / 2}\right) \times\left.\mathrm{BER}\right|_{\mathrm{SCM}}\right) \sqrt{\frac{\mathrm{N}_{\mathrm{o}} \mathrm{R}_{\mathrm{b}}}{3 \mathrm{~L} \log _{2} \mathrm{~L}}}
$$

Meanwhile, for MCM techniques, at the receiver end of view, the DC component of the signal detected by the PD is filtered out. Hence, by assuming a Gaussian noise distribution the SNR of the output signal can be presented as follows [34]

$$
\mathrm{SNR}=\frac{\overline{\mathrm{f}(\mathrm{t})^{2}}\left(\mathrm{R}_{\mathrm{r}} \mathrm{P}_{\mathrm{j}}^{\mathrm{Y}} \mathrm{M}_{\mathrm{i}}\right)^{2}}{\sigma^{2}}
$$

where $R_{r}$ is the responsivity of the $\mathrm{PD}$, $\sigma^{2}$ is the noise variance, $M_{i}$ is the modulation index, $f(t)$ is the normalized signal and $\overline{f(t)^{2}}$ is its average power. Under the assumption that the noise variance consists of shot and thermal noise added together [36]

$$
\begin{aligned}
& \sigma^{2}=\sigma_{\text {shot }}^{2}+\sigma_{\text {thermal }}^{2} \\
& \sigma^{2}=2 q\left[R\left[P_{j}^{r}\left(1+\left(M_{\text {indes }} \overline{f(t)}\right)^{2}\right)\right]+I_{b g} I_{2}\right] B+8-k T_{k} \eta A_{P D} B^{2}\left(\frac{I_{2}}{G}+\frac{2 \pi \eta_{p p D} B I_{3}}{g_{m}}\right)
\end{aligned}
$$

where $P_{j}^{r}\left(1+\left(M_{\text {index }} \overline{f(t)}\right)^{2}\right)$ is the total received power, $R$ is the transmitted symbol rate, $q$ is the electron charge, $T_{k}$ represents the absolute temperature, $k$ is the Boltzmann constant, and $B$ is the equivalent noise bandwidth. The rest of the parameters are listed in Table 1.

The BER of the M-QAM modulation scheme depends on $M$, total received power, and noise variance as a function of the symbol rate; hence it can be presented as [33]

$$
\left.\mathrm{BER}\right|_{\text {MCM }} \leq 0.2 \exp \left[\frac{-1.5 \overline{\mathrm{f}(\mathrm{t})^{2}}\left(\mathrm{R}_{\mathrm{r}} \mathrm{P}_{\mathrm{j}}^{\mathrm{r}} \mathrm{M}_{\mathrm{i}}\right)^{2}}{(\mathrm{M}-1) \sigma^{2}\left(\mathrm{P}_{\mathrm{j}}^{\mathrm{r}}\right)}\right]
$$

Where $\mathrm{M}$ is the signal constellation. 
Hence, the required LED lamp power $P_{\text {req. }}^{t}$ can be obtained from Eq. (10) as follows,

$$
\mathrm{P}_{\mathrm{req}}^{\mathrm{t}}=\frac{1}{\mathrm{R}_{\mathrm{r}} \mathrm{H}(0) \mathrm{M}_{\mathrm{i}}} \sqrt{\frac{\ln \left(\frac{\left.\left.\mathrm{BER}\right|_{\text {MCM. }}\right)(1-\mathrm{M}) \sigma^{2}\left(\mathrm{P}_{\mathrm{j}}^{\mathrm{r}}\right)}{0.2}\right.}{1.5 \overline{\mathrm{f}(\mathrm{t})^{2}}}}
$$

The proposed combination process of the scheme with M-QAM OFDM is shown in Fig. 3 and described as follows. A bipolar data stream is mapped through SC-LPPM, then the generated signal is modulated through the M-QAM OFDM (i.e., asymmetrically clipped optical (ACOOFDM) or DC-Biased optical (DCOOFDM)).

The generated optical signal is transmitted through the channel under AWGN assumption by the LED source.

After the optical signal is received at the receiving end by the $\mathrm{PD}$, the signal is demodulated to decompose it into the $\mathrm{M}$ QAM OFDM signal and the SC-LPPM signal.
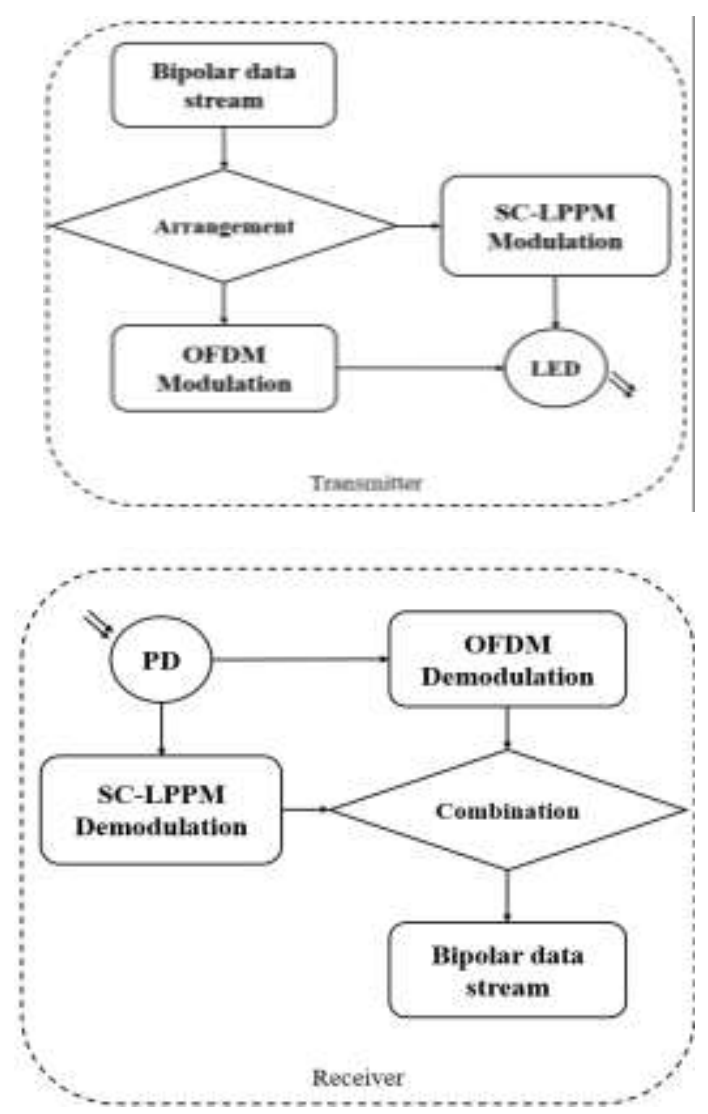

Fig. 3. Block diagram for the proposed combination process.

\section{SYSTEM SPECIFICATIONS}

The presented work assumes a typical configuration of a $5 \times 5 \times 3 \mathrm{~m}^{3}$ empty room that utilizes the lighting topologies presented in section 2, under a LOS assumption.

Table 1 presents the proposed room, sources, and receiver parameters. These values guarantee acceptable lighting and communication performance.

Table 1. Simulation parameters [35].

\begin{tabular}{|c|c|c|c|}
\hline & \multirow[b]{2}{*}{ Parameter } & \multicolumn{2}{|c|}{ Value } \\
\hline & & $\begin{array}{l}\text { Distinctive } \\
\text { lighting } \\
\text { layout }\end{array}$ & $\begin{array}{c}\text { Uniform } \\
\text { lighting } \\
\text { layout }\end{array}$ \\
\hline \multirow[t]{4}{*}{ Source } & Number of LEDs & $\begin{array}{c}3600 \\
(60 \times 60)\end{array}$ & $\begin{array}{c}500 \\
(20 \times 25)\end{array}$ \\
\hline & LED transmitted power & \multicolumn{2}{|c|}{$20 \mathrm{~mW}$} \\
\hline & Semi-angle half power & \multicolumn{2}{|c|}{$60^{\circ}$} \\
\hline & $\begin{array}{l}\text { Center luminous intensity } \\
\text { power spectrum density }\end{array}$ & \multicolumn{2}{|c|}{$\begin{array}{c}0.73 \mathrm{~cd} \\
10^{-21} \mathrm{~W} / \mathrm{Hz}\end{array}$} \\
\hline Room & $\begin{array}{c}\text { Room size } \\
\text { Height of desktop surface }\end{array}$ & \multicolumn{2}{|c|}{$\begin{array}{c}5 \times 5 \times 3 \mathrm{~m}^{3} \\
0.85 \mathrm{~m}\end{array}$} \\
\hline \multirow[t]{4}{*}{ Receiver } & Area & \multicolumn{2}{|c|}{$1 \mathrm{~cm}^{2}$} \\
\hline & Responsivity & \multicolumn{2}{|c|}{$0.4 \mathrm{~A} / \mathrm{W}$} \\
\hline & $\begin{array}{l}\text { Concentrator refractive } \\
\text { index }\end{array}$ & \multicolumn{2}{|c|}{1.5} \\
\hline & Filter gain & \multicolumn{2}{|c|}{1} \\
\hline Noise & Background current (Ibg) & \multicolumn{2}{|c|}{$5100 \mu \mathrm{A}$} \\
\hline Parameter & Noise bandwidth factor $\left(\mathrm{I}_{2}\right)$ & \multicolumn{2}{|c|}{0.562} \\
\hline & Field-effect transistor (FET) & \multicolumn{2}{|c|}{$30 \mathrm{~ms}$} \\
\hline & FET channel noise factor $(\Gamma)$ & \multicolumn{2}{|c|}{1.5} \\
\hline & Fixed capacitance $(\eta)$ & \multicolumn{2}{|c|}{$112 \mathrm{pF} / \mathrm{cm}^{2}$} \\
\hline & Open-loop voltage gain $(\mathrm{G})$ & \multicolumn{2}{|c|}{10} \\
\hline & $\mathrm{I}_{3}$ & \multicolumn{2}{|c|}{0.0868} \\
\hline
\end{tabular}

\section{RESULTS AND DISCUSSION}

By considering the proposed room and system specifications presented in section 2 and section 4, the following section holds the results of combing SCLPPM with optical OFDM techniques 
which will present an insight of the overall system BER and power performance under a wide range of operating bit rates.

Fig. 4 presents the BER performance of the system to the operating bit rate $\left(R_{b}\right)$ for the presented system at various values of modulation levels (L) under distinctive lighting topology assumption.

With the presumption that the receiver is allocated under the light sources, it can be shown that the system BER performance is inversely proportional to the operating bit rate. Moreover, it can be shown that the BER performance and behavior can be enhanced by using larger values of $L$.

From Fig. 4(a), It can be indicated that at low operating bitrate (i.e., 1 Mbps), a remarkable BER performance of $1.6 \times 10^{-6}$ can be achieved for $\mathrm{L}=8$, meanwhile utilizing the scheme at $\mathrm{L}=2$ and $\mathrm{L}=4$ failed to achieve the minimum BER performance required for sustaining a reliable communication link.

Increasing the data rates (i.e., 50 Mbps), resulted in achieving a BER performance of $10^{-1}$ modulation level $\mathrm{L}=2$, and a BER performance of $3 \times 10^{-2}$ at $\mathrm{L}=8$, which demonstrates the limitations of the scheme at higher data rates.

It can be indicated from Fig. 4(b) that a considerable improvement can be accomplished by utilizing OFDM techniques with SC- LPPM. It can also be shown that the performance of the scheme at low data rates (i.e., 1-2 Mbps) is enhanced compared to the performance indicated in Fig. 4(a), as a BER performance of $10^{-6}$ is achieved for $\mathrm{L}=2$ and $8.5 \times 10^{-8}$ for $\mathrm{L}=8$.

Meanwhile, an exceptional BER of $8.6 \times 10^{-5}$ can be accomplished at a bit rate of $50 \mathrm{Mbps}$, and at $\mathrm{L}=8$. Another observation can be made from Fig. 4(b), is that for high operating data rates, all of the modulation levels can meet the minimum BER of $10^{-3}$.

Moreover, it can be shown that the analysis at increased data rates, shows that the BER behavior of the scheme will start to saturate as the operating bit rates reaches $35 \mathrm{Mbps}$, which demonstrates the stability of the scheme as the data rates increases for more than 50Mbps.

Finally, it can be indicated that LOS/VLC systems utilizing SC- LPPM combined with MCM (i.e., OFDM) modulation techniques show a distinguishable BER improvement at lower bit rates and larger values of $L$. For a bit rate of $5 \mathrm{Mbps}$, a remarkable BER of $9.56 \times 10^{-6}$ is accomplished at $\mathrm{L}=8$.

It is noteworthy to mention that previous literature indicates that a BER performance of $10^{-3}$ is considered as the minimum acceptable BER to achieve a reliable communication link [33, 34].
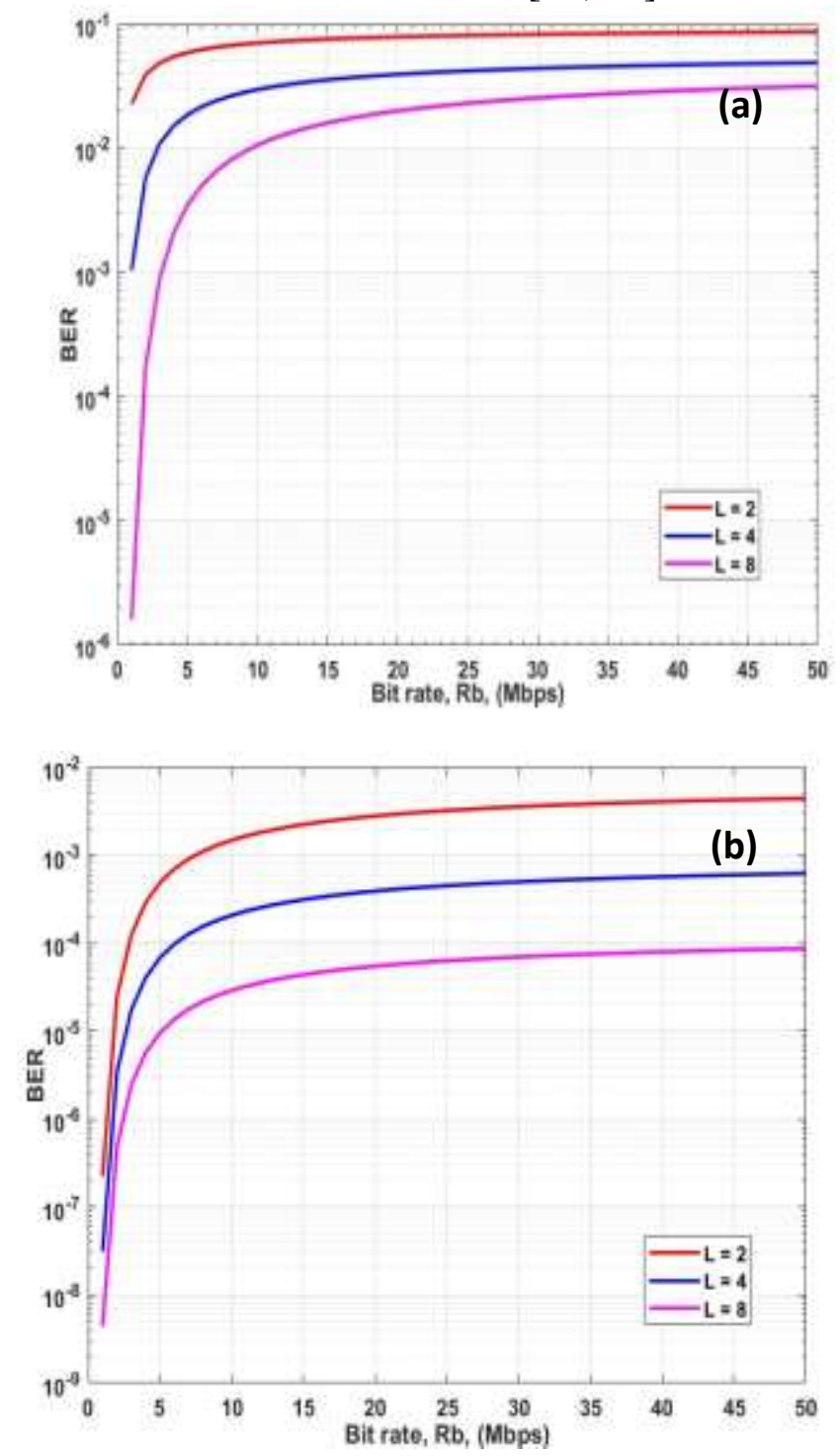

Fig. 4 BER vs. bit rate at different modulation levels (L) 
under distinctive lighting topology assumption for (a) without utilizing OFDM techniques, (b) by utilizing OFDM techniques.

For uniform lighting topology, Fig. 5 indicates the BER performance of the system to the operating bit rate $\left(\mathrm{R}_{\mathrm{b}}\right)$ for the presented system at various values of modulation levels (L).

It can be indicated from Fig. 5(a) shows at bitrate of 1 Mbps, a BER performance of $3.7 \times 10^{-3}$ at $\mathrm{L}=8$, meanwhile, the scheme BER performance decreases to $1.9 \times 10^{-2}$ and $5.9 \times 10^{-2}$ for $\mathrm{L}=4$ and $\mathrm{L}=2$, respectively.

Which can indicate that the scheme can barely achieve the minimum BER requirements of a reliable communication link at modulation level $\mathrm{L}=8$.

For higher operating data rates (i.e., 2 to $50 \mathrm{Mbps}$ ), it can be shown from Fig. 5(a) that the scheme will fail to achieve the minimum BER requirements for all of the modulation levels (i.e., $\mathrm{L}=2$, $\mathrm{L}=4$, and $\mathrm{L}=8$ ). It can be shown that for a data rate of $50 \mathrm{Mbps}$ and for $\mathrm{L}=8$ a BER performance of $4.5 \times 10^{-2}$ can be achieved.

It can be indicated from Fig. 5(b) that utilizing OFDM techniques with SCLPPM resulted in a noticeable enhancement to the BER performance. the performance of the scheme enhanced to 10 5 at data rate of $1 \mathrm{Mbps}$ for $\mathrm{L}=8$ and $\mathrm{L}=4$, and $5 \times 10^{-4}$ for $\mathrm{L}=2$.

Another observation can be made from Fig. 5(b), by increasing the data rates to 50 Mbps while utilizing optical OFDM techniques resulted in an acceptable BER performance for the scheme. It can be shown that the BER performance enhanced to $1.2 \times 10^{-4}$ at $\mathrm{L}=8,8.8 \times 10^{-4}$ at $\mathrm{L}=4$, and $6.3 \times 10^{-3}$ at $\mathrm{L}=2$.

Moreover, it can be indicated that utilizing optical OFDM techniques with SC- LPPM scheme resulted in satisfying the minimum BER required to sustain a reliable communication level at increased operating data rates.

Same behavior can be detected as indicated in Fig. 4(b), as the BER behavior of the scheme will start to saturate as the operating bit rates reaches $35 \mathrm{Mbps}$, which demonstrates the stability of the scheme as the data rates increases for more than $50 \mathrm{Mbps}$.

Finally, it can be can be concluded that utilizing the scheme under distinctive lighting topology assumption will result in enhanced BER performance compared to uniform lighting topology assumption.
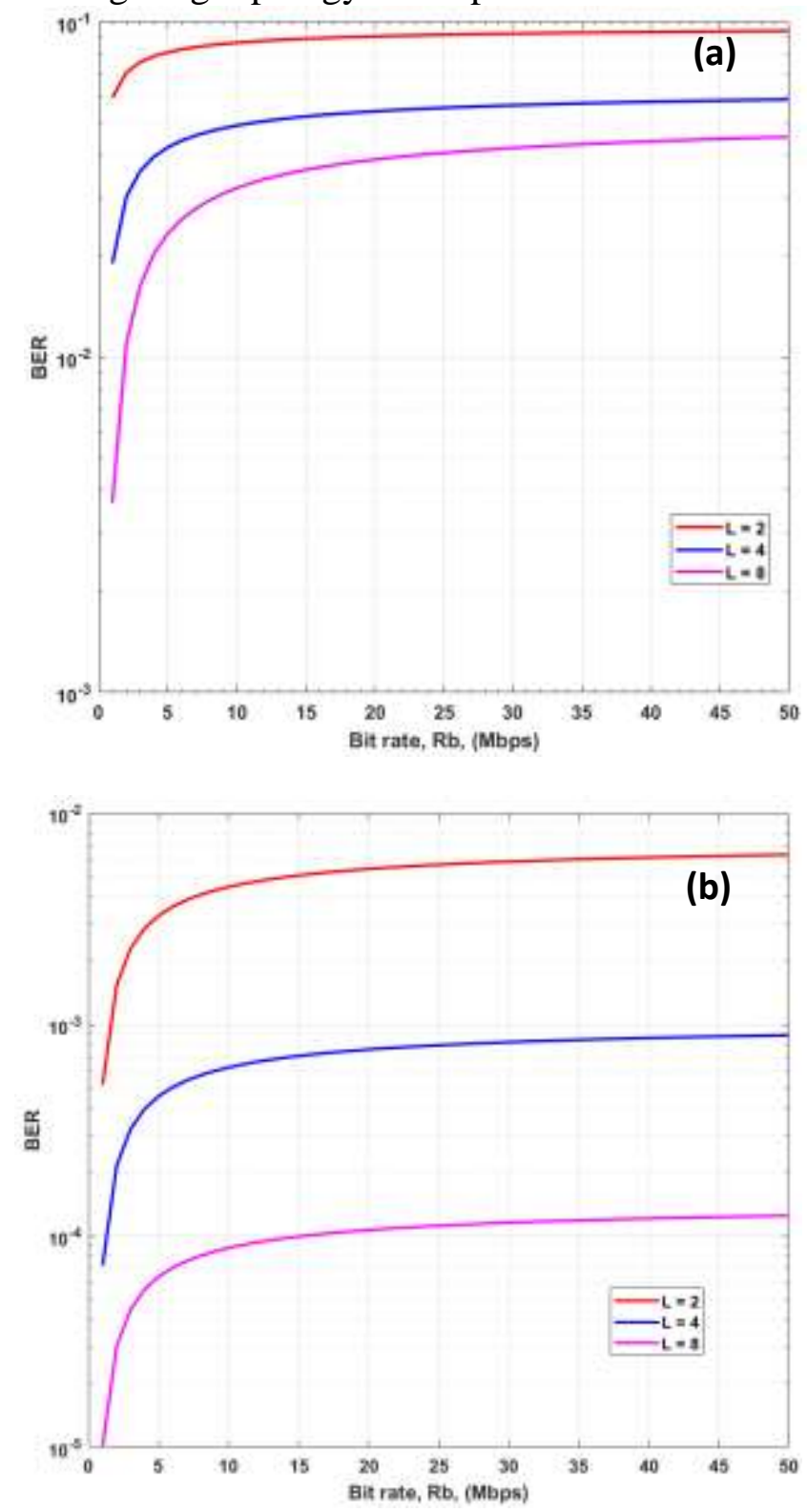

Fig. 5 BER vs. bit rate at different modulation levels (L) under uniform lighting topology assumption for (a) without utilizing OFDM techniques, (b) by utilizing OFDM techniques. 
Fig. 6 presents the minimum power required to utilize SC-LPPM technique for VLC systems versus the operating bit rate at various modulation levels (L) under distinctive lighting topology assumption. It can be indicated from Fig.6 that utilizing optical OFDM slightly increases the required transmitter power at lower modulation levels.

Fig. 6(a) indicates that the performance of SC-LPPM scheme at low data rates (i.e., $1 \mathrm{Mbps}$ ), it can be shown that the power requirements increased by approximately $2 \mathrm{dBm}$ as the modulation level changes from $\mathrm{L}=8$ to $\mathrm{L}=2$.

Moreover, it can be indicated from Fig. 6(a) that at $50 \mathrm{Mbps}$ the power requirements will increase to $8.8 \mathrm{dBm}$ for $\mathrm{L}=2$. Moreover, it can be observed that for $\mathrm{L}=2$ and $\mathrm{L}=4$, the required power will continue to increase in a noticeable way as the data rate increases, while for $\mathrm{L}=8$ the required power increases in a small margin which nominate this modulation level (i.e., $L=8$ ) to be used to save power.

However, analyzing the scheme performance at increased data rates, indicated the power saving capabilities of the scheme, as it can be shown that at $\mathrm{L}=2$, the power requirements increased by $30 \%$ as the data rate increased from $15 \mathrm{Mbps}$ to 50 Mbps. While at $\mathrm{L}=8$ the power requirements increased by $20 \%$ for the same increase in the data rates.

Fig. 6(b) demonstrates the power requirements of the scheme due to the utilization of optical OFDM schemes.

It can be shown that at low data rates (i.e., 1-5 Mbps), the power requirements increase by an approximate of $2 \mathrm{dBm}$ as the modulation level changes from $\mathrm{L}=8$ to $\mathrm{L}=4$, and increases approximately by $3 \mathrm{dBm}$ as the modulation level changes from $\mathrm{L}=4$ to $\mathrm{L}=8$.

Meanwhile, increasing the operating data rates (i.e., 50 Mbps) will approximately increase the power requirements of the scheme by the same ranges compared to the power performance at lower data rates.

Finally, Fig.6 shows that utilizing optical OFDM slightly increases the required transmitter power at higher modulation levels. It can be shown that by utilizing optical OFDM techniques, the LED transmitted power will be increased by $16 \mathrm{~mW}$. In other words, according to the lighting system layout assumed an LED module that consists of $60 \times 60$ LED array will consume a total power of 129.6 Watt by utilizing optical OFDM with SC-LPPM.

These power consumption levels can be considered to be lower than most types of conventional lighting systems (i.e., incandescent and fluorescent) which consume $60 \mathrm{~W} /$ lamp and 14 W/lamp respectively [38]. Which can be assumed as an admissible cost for achieving an enhanced BER performance especially at high operating system rates.

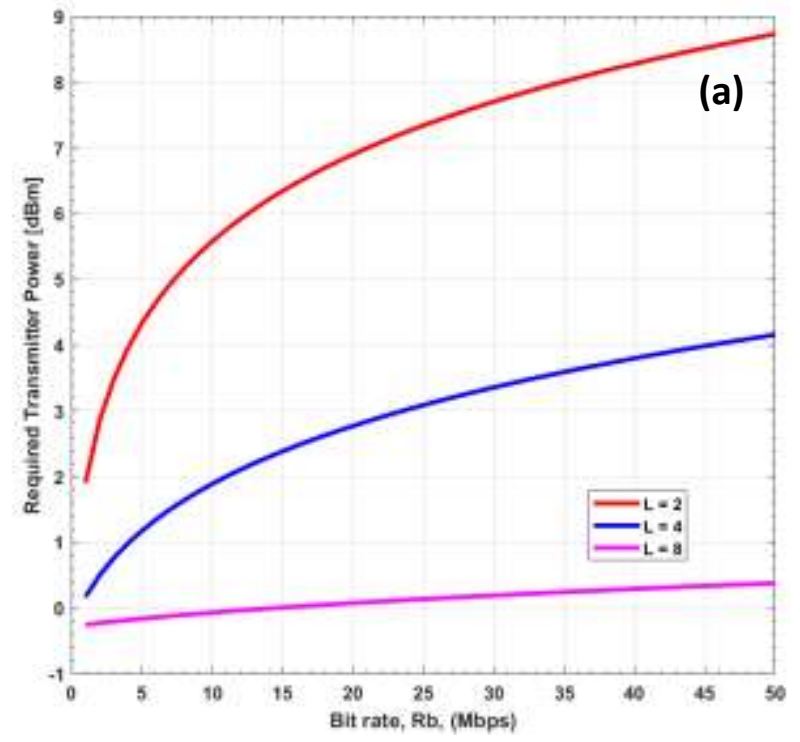




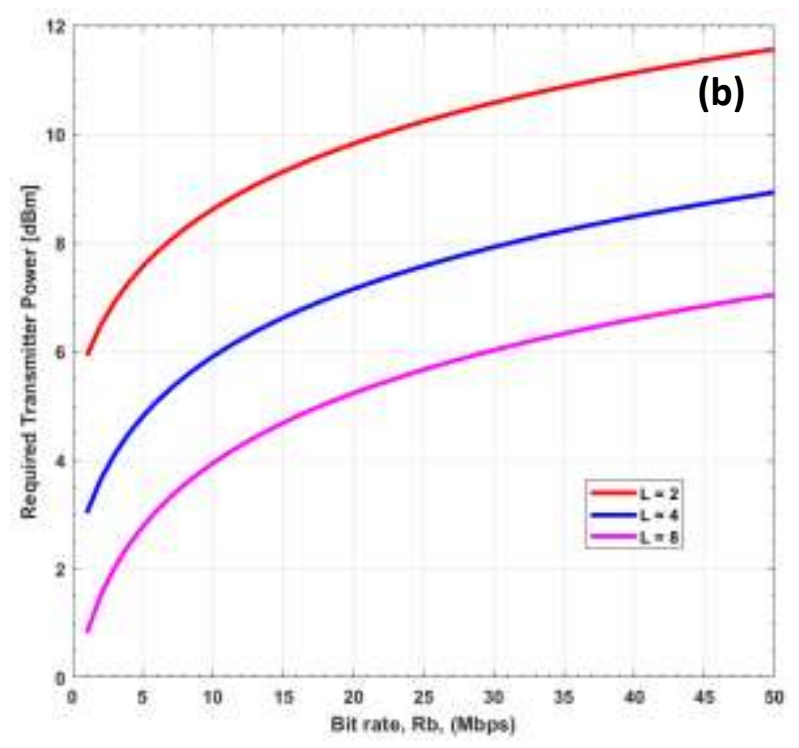

Fig. 6 Minimum transmitter power required vs bit rate at different modulation levels (L) under distinctive lighting topology assumption for (a) without utilizing OFDM techniques, (b) by utilizing OFDM techniques.

Under uniform lighting topology assumption, Fig. 7 indicates the minimum required power for utilizing SC-LPPM technique for VLC systems versus the operating bit rate at various modulation levels (L) under uniform lighting topology assumption. from Fig. 7, it can be indicated that utilizing optical OFDM shows the same behavior as in Fig. 6, the power requirements is increased as the data rate increases.

From Fig. 7(a), same behavior as in distinctive lighting topology can be identified, but at lower levels. At $1 \mathrm{Mbps}$, a transmitter power of $-3.714 \mathrm{dBm}$ is required at $\mathrm{L}=8,-2.357 \mathrm{dBm}$ at $\mathrm{L}=4$, and $0.822 \mathrm{dBm}$ at $\mathrm{L}=2$.

Moreover, it can be indicated from Fig. 7(a) that at $50 \mathrm{Mbps}$ the power requirements will increase to $8.6 \mathrm{dBm}$ for $\mathrm{L}=2$ which is almost an identical requirement as for the distinctive lighting topology. However, for a minimum LED power of $3.5 \mathrm{dBm}$ and $-2.2 \mathrm{dBm}$ are required at $\mathrm{L}=4$ and $\mathrm{L}=8$, respectively, which is lower power requirement compared to the distinctive lighting topology requirements.
Same behavior is indicated as in Fig. 6(a); at $\mathrm{L}=8$ the required power increases by a small margin which nominate $\mathrm{L}=8$ to be used for power saving purposes, while for $\mathrm{L}=2$ and $\mathrm{L}=4$, power requirements will continue to increase in a noticeable way as the data rate increases.

However, analyzing the scheme performance at increased data rates, it can be indicated that increasing the data rates under uniform lighting topology assumption will increase the power requirements margin compared to the distinctive lighting topology, it can be shown that at $\mathrm{L}=8$ the power requirements increased by $26 \%$ as the data rate increased from $15 \mathrm{Mbps}$ to $50 \mathrm{Mbps}$, while at $\mathrm{L}=2$, the power requirements increased by $42 \%$ for the same increase in the data rates.

Fig. 7(b) shows the power requirements of the scheme due to the utilization of optical OFDM schemes under uniform lighting topology assumption.

It can be indicated that, for a data rate of 50 Mbps utilizing optical OFDM under uniform lighting topology assumption increases the power requirements by $414 \%$ at $\mathrm{L}=8,148 \%$ at $\mathrm{L}=4$, and $32 \%$ at $\mathrm{L}=2$. Which demonstrates the low power performance of scheme when utilized for uniform lighting topology especially when compared to the power performance of the distinctive lighting topology.

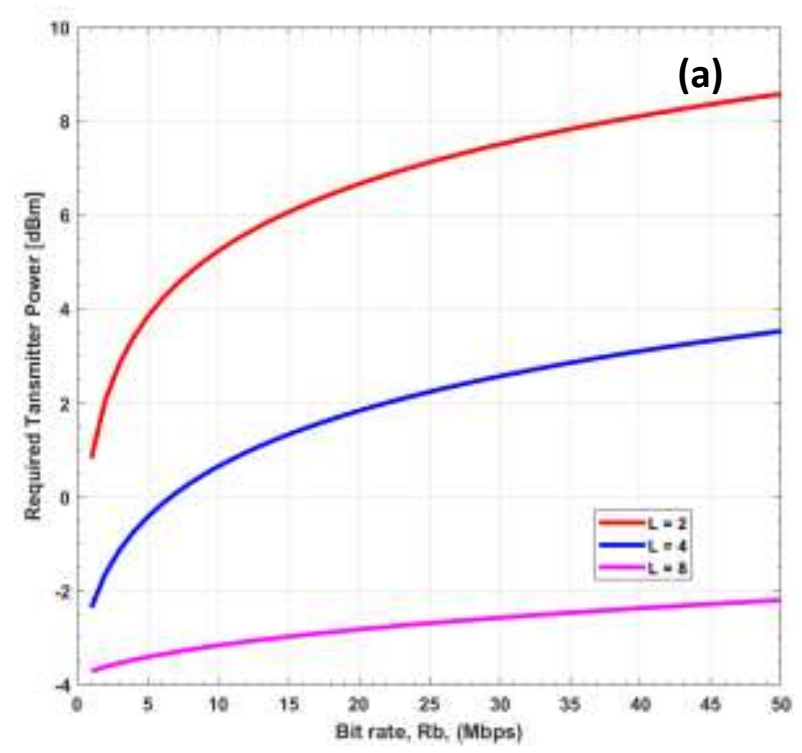




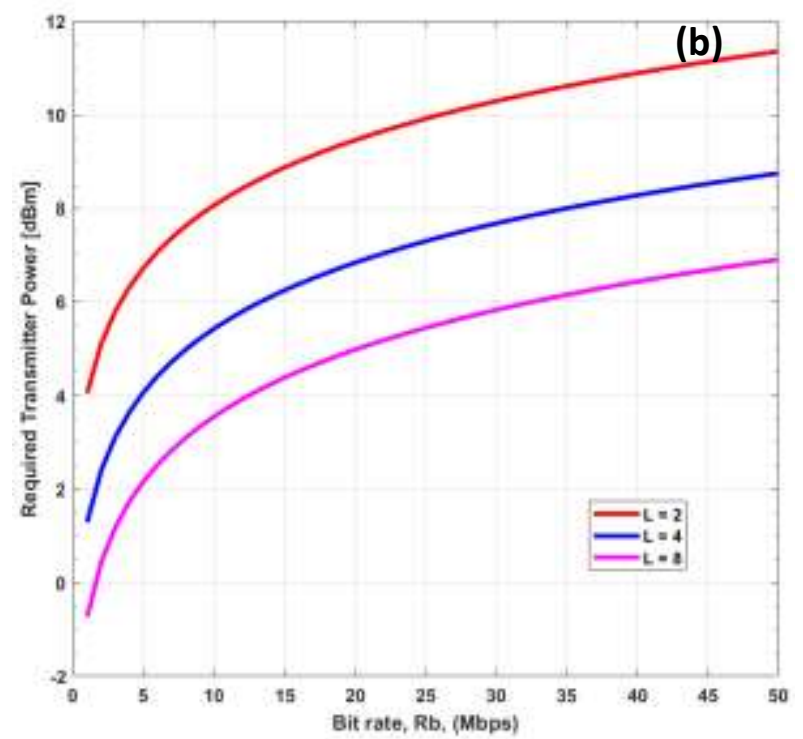

Fig. 7 Minimum transmitter power required vs. bit rate at different modulation levels (L) under uniform lighting topology assumption for (a) without utilizing OFDM techniques, (b) by utilizing OFDM techniques.

The power distribution across the proposed distinctive lighting topology for utilizing SC- LPPM techniques as an SCM technique and combined with optical OFDM techniques is presented in Fig. 8.

From Fig. 8(a) it can be indicated that the received optical power increases from $2.69 \mathrm{dBm}$ at the room corners to $6.59 \mathrm{dBm}$ under the ceiling lights of the room. The most powerful LOS components are under four LED modules and moderately fall as the receiver moves to the room corners.

Fig. 8(b) indicates that although utilizing optical OFDM increases the required transmitter power, the optical power received by the receiver is enhanced, which is an extra advantage to enhance the operating data rates at a remarkable BER performance as previously discussed. The optical power received under the light source is $10.12 \mathrm{dBm}$ which decreases as the receiver is located towards the room corners to $6.13 \mathrm{dBm}$.
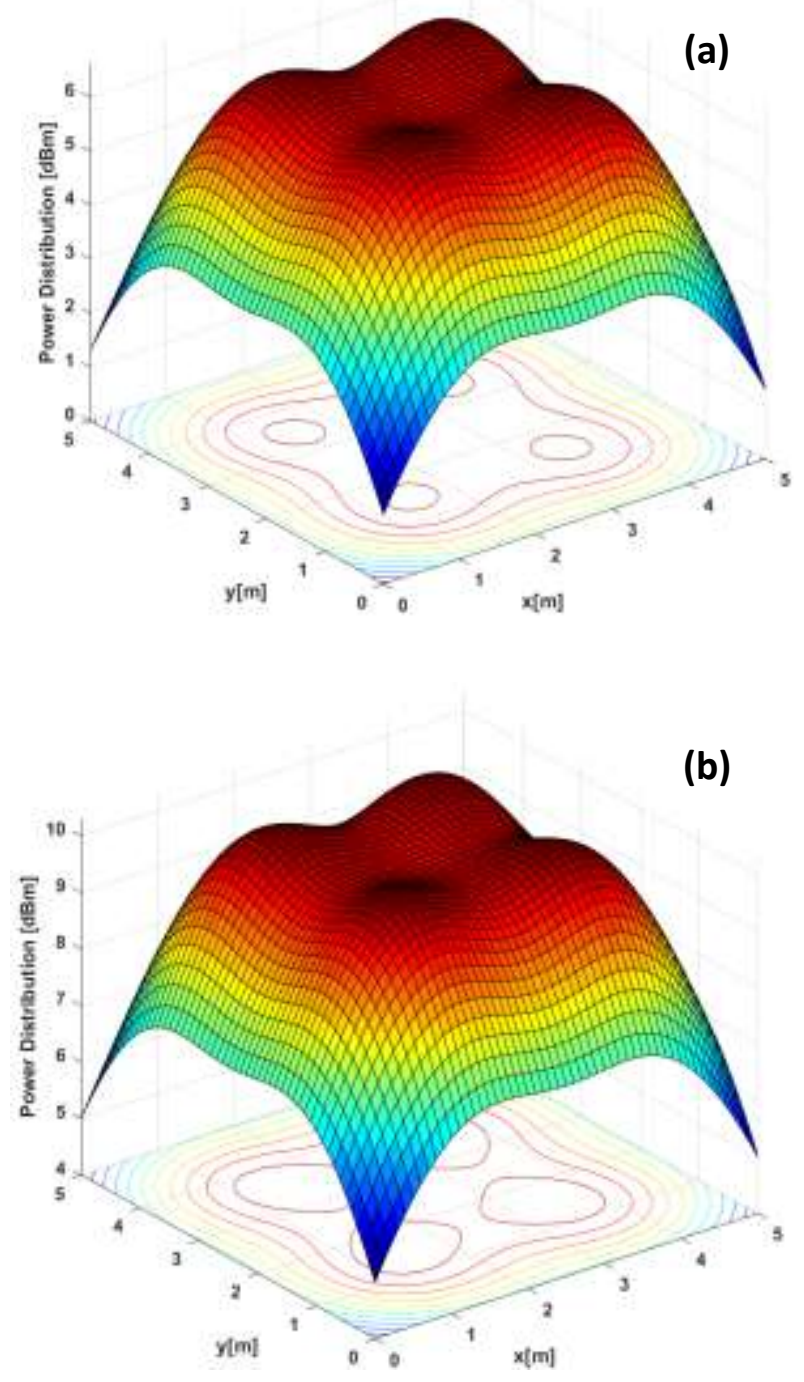

Fig. 8 Power distribution across the proposed room under distinctive lighting topology assumption for SC- LPPM (a) without utilizing OFDM techniques, (b) by utilizing OFDM techniques.

Meanwhile, for uniform lighting topology, Fig. 9 shows the power distribution for utilizing SC- LPPM techniques as an SCM technique and combined with optical OFDM techniques.

Fig. 9(a) shows the power performance of the scheme as a SCM modulation technique, it can be indicated that the strongest received component of $-3.3 \mathrm{dBm}$ will be detected by the receiver at the room center, meanwhile, the received optical power will decrease as the receiver locates towards the room corners to $-6.575 \mathrm{dBm}$. 

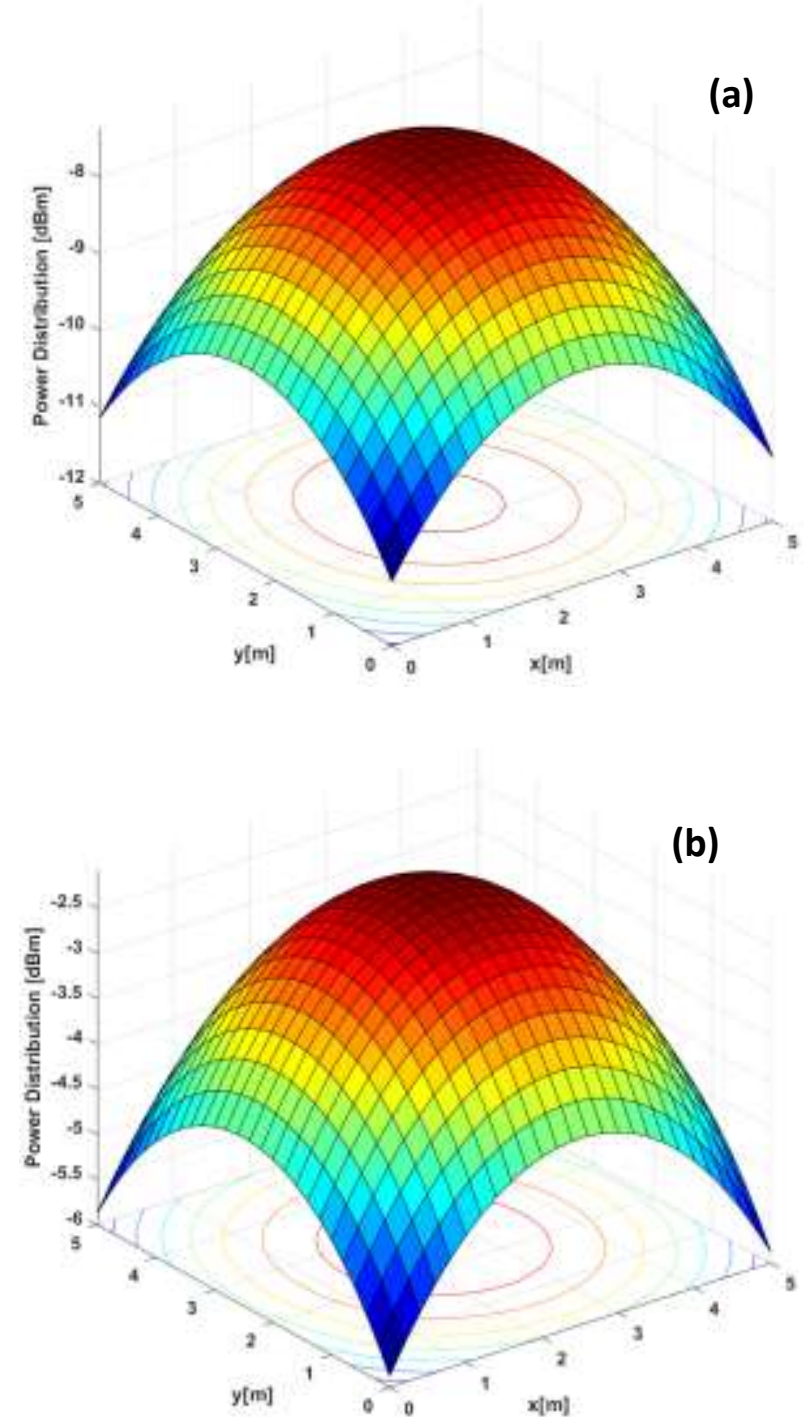

Fig. 9 Power distribution across the proposed room under uniform lighting topology assumption for SC- LPPM (a) without utilizing OFDM techniques, (b) by utilizing OFDM techniques.

Fig. 9(b) indicates that utilizing optical OFDM with SC-LPPM will show the same behavior as in the distinctive lighting topology by increasing the total received power.

It can be observed from Fig. 9(b), that the maximum received optical power across the room will increase to $-2 \mathrm{dBm}$ (i.e., $39 \%$ ) at the center of the room when optical OFDM is utilized, while the minimum optical power received at the corners of the room is increased to -4.5 $\mathrm{dBm}$ (i.e., $31.6 \%$ ).

\section{SURVEY ON DIFFERENT MODULATION TECHNIQUES PRESENTED IN PREVIOUS LITERATURE}

Several works of literature investigated and evaluated the performance of different SCM techniques, moreover, this literature aims to achieve a unique BER performance at enhanced data rates. But, due to design complexity not all of this literature investigated the combination process with optical OFDM techniques.

Moreover, it is noteworthy to mention that a lack in investigating different VLC modulation techniques under uniform lighting topology assumption can be indicated through scanning previous literatures.

Table 2 holds a survey on several techniques investigated by previous literature, their maximum achieved BER and power performance. This data is then compared with the results obtained from the presented work.

From Table 2, it can be indicated that SC- LPPM technique can achieve high operating data rates up to $50 \mathrm{Mbps}$ with a remarkable power-saving performance when combined with optical OFDM techniques. 
Vol.42, No.1. January2023

Table 2. Survey on different modulation techniques presented in previous literature.

\begin{tabular}{|c|c|c|c|c|c|c|c|c|c|c|c|c|}
\hline \multirow[b]{3}{*}{ Ref. } & \multirow[b]{3}{*}{$\begin{array}{l}\text { Evaluated } \\
\text { techniques }\end{array}$} & \multicolumn{11}{|c|}{ OFDM utilization } \\
\hline & & \multicolumn{6}{|c|}{ Without utilizing optical OFDM } & \multicolumn{5}{|c|}{ After utilizing optical OFDM } \\
\hline & & $\begin{array}{c}\text { No. of } \\
\text { LED } \\
\text { lamps }\end{array}$ & $\begin{array}{c}\text { Achieved } \\
\text { BER }\end{array}$ & $\begin{array}{l}\text { Achieved } \\
\text { data rate }\end{array}$ & $\begin{array}{c}\mathrm{P}_{\mathrm{req}}^{\mathrm{t}} \\
{[\mathbf{d B m}]}\end{array}$ & $\begin{array}{c}\text { Min. } \\
\mathrm{P}_{1}^{\mathrm{r}} \\
{[\mathbf{d B m}]}\end{array}$ & $\begin{array}{c}\text { Max. } \\
\mathrm{P}_{1}^{\mathrm{r}} \\
{[\mathbf{d B m}]} \\
\end{array}$ & $\begin{array}{c}\text { Achieved } \\
\text { BER }\end{array}$ & $\begin{array}{l}\text { Achieved } \\
\text { data rate }\end{array}$ & $\begin{array}{c}\mathrm{P}_{\text {req. }}^{\mathrm{t}} \\
{[\mathbf{d B m}]}\end{array}$ & $\begin{array}{c}\text { Min. } P_{1}^{r} \\
{[\mathrm{dBm}]}\end{array}$ & $\begin{array}{c}\operatorname{Max} . \mathrm{P}_{1}^{\mathrm{r}} \\
{[\mathrm{dBm}]}\end{array}$ \\
\hline 39 & CSK & 1 & $3 \times 10^{-1}$ & $2 \times 10^{6}$ & $\begin{array}{c}\text { Not } \\
\text { Evaluated }\end{array}$ & $\begin{array}{c}\text { Not } \\
\text { Evaluated }\end{array}$ & $\begin{array}{c}\text { Not } \\
\text { Evaluated }\end{array}$ & $\begin{array}{c}\text { Not } \\
\text { Evaluated }\end{array}$ & $\begin{array}{c}\text { Not } \\
\text { Evaluated }\end{array}$ & $\begin{array}{c}\text { Not } \\
\text { Evaluated }\end{array}$ & $\begin{array}{c}\text { Not } \\
\text { Evaluated }\end{array}$ & $\begin{array}{c}\text { Not } \\
\text { Evaluated }\end{array}$ \\
\hline 40 & PPM & 1 & $10^{-6}$ & $19.4 \times 10^{6}$ & $\begin{array}{c}\text { Not } \\
\text { Evaluated }\end{array}$ & $\begin{array}{c}\text { Not } \\
\text { Evaluated }\end{array}$ & $\begin{array}{c}\text { Not } \\
\text { Evaluated }\end{array}$ & $\begin{array}{c}\text { Not } \\
\text { Evaluated }\end{array}$ & $\begin{array}{c}\text { Not } \\
\text { Evaluated }\end{array}$ & $\begin{array}{c}\text { Not } \\
\text { Evaluated }\end{array}$ & $\begin{array}{c}\text { Not } \\
\text { Evaluated }\end{array}$ & $\begin{array}{c}\text { Not } \\
\text { Evaluated }\end{array}$ \\
\hline 35 & SC- LPPM & 4 & $2.25 \times 10^{-6}$ & $3 \times 10^{6}$ & -0.0307 & 2.75 & 8 & $\begin{array}{c}\text { Not } \\
\text { Evaluated }\end{array}$ & $\begin{array}{c}\text { Not } \\
\text { Evaluated }\end{array}$ & $\begin{array}{c}\text { Not } \\
\text { Evaluated }\end{array}$ & $\begin{array}{c}\text { Not } \\
\text { Evaluated }\end{array}$ & $\begin{array}{c}\text { Not } \\
\text { Evaluated }\end{array}$ \\
\hline \multirow{3}{*}{41} & DIPPM & 4 & $10^{-6}$ & $1 \times 10^{6}$ & 11 & 21 & 26.5 & \multirow{3}{*}{$\begin{array}{l}\text { Not } \\
\text { Evaluated } \\
\text { Not } \\
\text { Evaluated } \\
\quad \text { Not } \\
\text { Evaluated }\end{array}$} & \multirow{3}{*}{$\begin{array}{c}\text { Not } \\
\text { Evaluated } \\
\text { Not } \\
\text { Evaluated } \\
\text { Not } \\
\text { Evaluated }\end{array}$} & \multirow{3}{*}{$\begin{array}{c}\text { Not } \\
\text { Evaluated } \\
\text { Not } \\
\text { Evaluated } \\
\quad \text { Not } \\
\text { Evaluated }\end{array}$} & \multirow{3}{*}{$\begin{array}{c}\text { Not } \\
\text { Evaluated } \\
\text { Not } \\
\text { Evaluated } \\
\text { Not } \\
\text { Evaluated }\end{array}$} & \multirow{3}{*}{$\begin{array}{c}\text { Not } \\
\text { Evaluated } \\
\text { Not } \\
\text { Evaluated } \\
\text { Not } \\
\text { Evaluated }\end{array}$} \\
\hline & SC- LPPM & 4 & $10^{-6}$ & $1 \times 10^{6}$ & -0.1064 & 1.5 & 7 & & & & & \\
\hline & M-VPPM & 4 & $10^{-5}$ & $23 \times 10^{6}$ & 16 & 23 & 29 & & & & & \\
\hline 16 & PWM & 1 & $\begin{array}{c}\text { Not } \\
\text { Evaluated }\end{array}$ & $\begin{array}{c}\text { Not } \\
\text { Evaluated }\end{array}$ & $\begin{array}{c}\text { Not } \\
\text { Evaluated }\end{array}$ & $\begin{array}{c}\text { Not } \\
\text { Evaluated }\end{array}$ & $\begin{array}{c}\text { Not } \\
\text { Evaluated }\end{array}$ & $10^{-3}$ & $50 \times 10^{6}$ & 36.13 & $\begin{array}{c}\text { Not } \\
\text { Evaluated }\end{array}$ & $\begin{array}{c}\text { Not } \\
\text { Evaluated }\end{array}$ \\
\hline \multirow{2}{*}{17} & PWM & 1 & $\begin{array}{c}\text { Not } \\
\text { Evaluated }\end{array}$ & $\begin{array}{c}\text { Not } \\
\text { Evaluated }\end{array}$ & $\begin{array}{c}\text { Not } \\
\text { Evaluated }\end{array}$ & $\begin{array}{c}\text { Not } \\
\text { Evaluated }\end{array}$ & $\begin{array}{c}\text { Not } \\
\text { Evaluated }\end{array}$ & $10^{-3}$ & $50 \times 10^{6}$ & 42.28 & \multirow{2}{*}{$\begin{array}{c}\text { Not } \\
\text { Evaluated } \\
\text { Not } \\
\text { Evaluated }\end{array}$} & \multirow{2}{*}{$\begin{array}{c}\text { Not } \\
\text { Evaluated } \\
\text { Not } \\
\text { Evaluated }\end{array}$} \\
\hline & MPPM & 1 & $\begin{array}{c}\text { Not } \\
\text { Evaluated }\end{array}$ & $\begin{array}{c}\text { Not } \\
\text { Evaluated }\end{array}$ & $\begin{array}{c}\text { Not } \\
\text { Evaluated }\end{array}$ & $\begin{array}{c}\text { Not } \\
\text { Evaluated }\end{array}$ & $\begin{array}{c}\text { Not } \\
\text { Evaluated }\end{array}$ & $10^{-3}$ & $49 \times 10^{6}$ & 40.68 & & \\
\hline \multirow{5}{*}{37} & PWM & 4 & $\begin{array}{c}\text { Not } \\
\text { Evaluated }\end{array}$ & $\begin{array}{c}\text { Not } \\
\text { Evaluated }\end{array}$ & $\begin{array}{c}\text { Not } \\
\text { Evaluated }\end{array}$ & $\begin{array}{c}\text { Not } \\
\text { Evaluated }\end{array}$ & $\begin{array}{c}\text { Not } \\
\text { Evaluated }\end{array}$ & $10^{-3}$ & $50 \times 10^{6}$ & 36.31 & \multirow{5}{*}{\multicolumn{2}{|c|}{$\begin{array}{cc}\quad \text { Not } & \text { Not } \\
\text { Evaluated } & \text { Evaluated } \\
\text { Not } & \text { Not } \\
\text { Evaluated } & \text { Evaluated } \\
\text { Not } & \text { Not } \\
\text { Evaluated } & \text { Evaluated } \\
\text { Not } & \text { Not } \\
\text { Evaluated } & \text { Evaluated } \\
\text { Not } & \text { Not } \\
\text { Evaluated } & \text { Evaluated }\end{array}$}} \\
\hline & MPPM & 4 & $\begin{array}{c}\text { Not } \\
\text { Evaluated }\end{array}$ & $\begin{array}{c}\text { Not } \\
\text { Evaluated }\end{array}$ & $\begin{array}{c}\text { Not } \\
\text { Evaluated }\end{array}$ & $\begin{array}{c}\text { Not } \\
\text { Evaluated }\end{array}$ & $\begin{array}{c}\text { Not } \\
\text { Evaluated }\end{array}$ & $10^{-3}$ & $49 \times 10^{6}$ & 36.27 & & \\
\hline & VPPM & 4 & $\begin{array}{c}\text { Not } \\
\text { Evaluated }\end{array}$ & $\begin{array}{c}\text { Not } \\
\text { Evaluated }\end{array}$ & $\begin{array}{c}\text { Not } \\
\text { Evaluated }\end{array}$ & $\begin{array}{c}\text { Not } \\
\text { Evaluated }\end{array}$ & $\begin{array}{c}\text { Not } \\
\text { Evaluated }\end{array}$ & $10^{-3}$ & $40 \times 10^{6}$ & 35.83 & & \\
\hline & CSK & 4 & $\begin{array}{c}\text { Not } \\
\text { Evaluated }\end{array}$ & $\begin{array}{c}\text { Not } \\
\text { Evaluated }\end{array}$ & $\begin{array}{c}\text { Not } \\
\text { Evaluated }\end{array}$ & $\begin{array}{c}\text { Not } \\
\text { Evaluated }\end{array}$ & $\begin{array}{c}\text { Not } \\
\text { Evaluated }\end{array}$ & $10^{-3}$ & $49.17 \times 10^{6}$ & 36.26 & & \\
\hline & SC- LPPM & 4 & $\begin{array}{c}\text { Not } \\
\text { Evaluated }\end{array}$ & $\begin{array}{c}\text { Not } \\
\text { Evaluated }\end{array}$ & $\begin{array}{c}\text { Not } \\
\text { Evaluated }\end{array}$ & $\begin{array}{c}\text { Not } \\
\text { Evaluated }\end{array}$ & $\begin{array}{c}\text { Not } \\
\text { Evaluated }\end{array}$ & $10^{-3}$ & $37.5 \times 10^{6}$ & 35.69 & & \\
\hline $\begin{array}{l}\text { In this } \\
\text { work }\end{array}$ & SC- LPPM & 4 & $2.25 \times 10^{-6}$ & $3 \times 10^{6}$ & -0.1064 & 2.69 & 6.59 & $8.6 \times 10^{-5}$ & $50 \times 10^{6}$ & 7.048 & 6.13 & 10.12 \\
\hline
\end{tabular}




\section{CONCLUSION}

In the presented work SC-LPPM modulation technique performance is investigated after being combined with $\mathrm{M}$ QAM OFDM under the assumption of two lighting topologies (i.e., distinctive lighting topology and uniform lighting topology).

For distinctive lighting topology, it can be indicated through the manuscript that utilizing optical OFDM with SC- LPPM resulted in increased operating bit rates up to $50 \mathrm{Mbps}$ with a remarkable BER performance of $8.6 \times 10^{-5}$ with an acceptable increase in the required transmitter power of $16 \mathrm{~mW}$. Meanwhile, it can be shown that utilizing optical OFDM with SC- LPPM enhances the received optical power distribution across the proposed room topology to $10.12 \mathrm{dBm}$.

By investigating the scheme under uniform lighting topology assumption, it was found that the scheme BER performance was decreased compared to the performance under the distinctive lighting assumption. for the uniform lighting topology, utilizing SC-LPPM as a SCM technique, the BER performance will fail to achieve the minimum BER performance required to sustain a reliable communication link.

Meanwhile, combining the scheme with M-QAM OFDM will enhance the BER performance up to $10^{-5}$.

By comparing the power performance under uniform lighting topology assumption to the distinctive lighting topology. It can be found that the minimum required transmitter power increases (i.e., up to $42 \%$ ) when SC-LPPM scheme is utilized as a SCM technique for uniform lighting topology. Moreover, a significant increase (i.e., up to $414 \%$ ) can be indicated when M-QAM OFDM is utilized.

Finally, it was found that for uniform lighting topology, the minimum power required to achieve an acceptable BER performance cannot be detected when the receiver is located at the corners of the proposed room.

\section{REFERENCES}

[1] A. Jovicic, J. Li and T. Richardson. Visible light communication: opportunities, challenges and the path to market, IEEE Communications Magazine, 51(12), pp.26-32, 2013.

[2] T. Komine, and M. Nakagawa. Fundamental analysis for visible-light communication system using LED lights. IEEE transactions on Consumer Electronics, 50(1), pp.100-107, 2004.

[3] Z. Ghassemlooy, W. Popoola and S. Rajbhandari. Optical wireless communications: system and channel modelling with Matlab®. CRC press, 2019.

[4] J. Armstrong, Y. A. Sekercioglu, and A. Neild. Visible light positioning: a roadmap for international standardization. IEEE Communications Magazine,51(12), pp.68-73, 2013.

[5] H. Elgala, R. Mesleh, and H. Haas. Indoor optical wireless communication: potential and state-of-the-art. IEEE Communications Magazine, 49(9), pp.56-62, 2011.

[6] L. Grobe, A. Paraskevopoulos, J. Hilt, et al. High-speed visible light communication systems. IEEE communications magazine, 51(12), pp.60-66, 2013.

[7] N. A. Mohammed, M. R. Abaza and M.H. Aly. Improved Performance of M-ary PPM in Different Free-Space Optical Channels due to Reed Solomon Code Using APD. International Journal of Scientific \& Engineering Research, 2(4), pp. 1-4, 2011

[8] N. A. Mohammed, H. S. A. Elnasr. and M. H. Aly. Performance evaluation and enhancement of $2 \times 2$ Ti: liNbO3 Mach Zehnder interferometer switch at $1.3 \mu \mathrm{m}$ and $1.55 \mu \mathrm{m}$. The Open Electrical \& Electronic Engineering Journal, 6(1), 2012. http://dx.doi.org/10.2174/1874129001206010036

[9] N. A. Mohammed, H. S. A. Elnasr. and M. H. Aly. Analysis and Design of an Electro-Optic 2x2 Switch Using Ti: KNbO3 as a Waveguide Based on MZI at $1.3 \mu \mathrm{m}$. Optical and Quantum Electronics, 46(2), pp.295-304, 2014. http://dx.doi.org/10.1007/s11082-013-9760-7

[10] M. I. Shehata, and N. A. Mohammed. Design and optimization of novel two inputs optical logic gates (NOT, AND, OR and NOR) based on single commercial TW-SOA operating at 40 Gbit/s. Optical and Quantum Electronics, 48(6), pp.1-16, 2016.

http://dx.doi.org/ 10.1007/s11082-016-0602-2

[11] N. A. Mohammed, N. M. Okasha, M. H. Aly. A wideband apodized FBG dispersion compensator in long haul WDM systems, Journal of Optoelectronics and Advanced Materials, 18(56), pp. 475-479, 2016.

[12]N. A. Mohammed, and H. O. El Serafy. Ultrasensitive quasi-distributed temperature sensor based on an apodized fiber Bragg grating. Applied Optics, 57(2), pp.273-282, 2018. https://doi.org/10.1364/AO.57.000273

[13] N. A. Mohammed, and N. M. Okasha. Single-and dual-band dispersion compensation unit using apodized chirped fiber Bragg grating. Journal of Computational Electronics, 17(1), pp.349-360, 2018. https://doi.org/10.1007/s10825-017-1096-

[14] T. S. Mostafa, N. A. Mohammed, and E.S.M. ElRabaie. Ultracompact ultrafast-switching-speed all-optical $4 \times 2$ encoder based on photonic crystal. Journal of Computational Electronics, 18(1), pp.279-292, 2019. 
https://doi.org/10.1007/s10825-018-1278-6

[15] T. S. Mostafa, N. A. Mohammed, and E.S.M. ElRabaie. Ultra-High bit rate all-optical AND/OR logic gates based on photonic crystal with multiwavelength simultaneous operation. Journal of Modern Optics, 66(9), pp.1005-1016, 2019. https://doi.org/10.1080/09500340.2019.1598587

[16] N. A. Mohammed, M. M. Hamed, A. A. Khalaf, and S. EL-Rabaie. Malaria biosensors with ultrasensitivity and quality factor based on cavity photonic crystal designs. The European Physical Journal Plus, 135(11), pp.1-22, 2020. https://doi.org/10.1140/epjp/s13360-020-00940-5

[17] N. A. Mohammed, M. M. Hamed, A. A. Khalaf, A. Alsayyari, et al. High-sensitivity ultra-quality factor and remarkable compact blood components biomedical sensor based on nanocavity coupled photonic crystal. Results in Physics, 14, p.102478, 2019.

https://doi.org/10.1016/j.rinp.2019.102478

[18] N. A. Mohammed, and H. Mansi. Performance Enhancement and Capacity Enlargement for a DWDM-PON System Utilizing an Optimized Cross Seeding Rayleigh Backscattering Design. Applied Sciences, 9(21), p.4520, 2019. https://doi.org/10.3390/app9214520

[19] M. Abd Elkarim, N. A. Mohammed, and M. H. Aly. Exploring the performance of indoor localization systems based on VLC-RSSI, including the effect of NLOS components using two light-emitting diode lighting systems. Optical Engineering, 54(10), p.105110, 2015. http://dx.doi.org/10.1117/1.OE.54.10.105110

[20]N. A. Mohammed and M. Abd Elkarim. Exploring the effect of diffuse reflection on indoor localization systems based on RSSIVLC. Optics express, 23(16), pp.20297-20313, 2015.

https://doi.org/10.1364/OE.23.020297

[21]I. Din, andH. Kim. Energy-efficient brightness control and data transmission for visible light communication. IEEE photonics technology letters, 26(8), pp.781-784, 2014.

[22] A. Khalid, and H. M. Asif. OCDMA and OSTBC based VLC transceiver design using NI cDAQ . Photonic Network Communications, 35(1), pp.97-108, 2018.

[23]C. Quintana, V. Guerra, J. Rufo, et al. Reading lamp-based visible light communication system for in-flight entertainment. IEEE Transactions on Consumer Electronics, 59(1), pp.31-37, 2013.

[24] T. Yamazato, I. Takai, H. Okada, et al. Imagesensor-based visible light communication for automotive applications. IEEE Communications Magazine, 52(7), pp.88-97, 2014.

[25]A. C. Boucouvalas, P. Chatzimisios, Z. Ghassemlooy, et al. Standards for indoor optical wireless communications. IEEE Communications Magazine, 53(3), pp.24-31, 2015.

[26] I. C. Rust, and H. H. Asada. A dual-use visible light approach to integrated communication and localization of underwater robots with application to non-destructive nuclear reactor inspection. In 2012 IEEE International Conference on Robotics and Automation (pp. 2445-2450). IEEE, 2012.

[27]C. G. Lee. Visible Light Communication, Advanced Trends in Wireless Communications. Paterson, NJ, USA: Mutamed Khalid, 2011.

[28] K. Lee, and H. Park. Modulations for visible light communications with dimming control. IEEE photonics technology letters, 23(16), pp.1136-1138, 2011.

[29] S. Dimitrov, and H. Haas. Principles of LED light communications: towards networked Li-Fi. Cambridge University Press, 2015.

[30] J. M. Kahn, and J. R. Barry. Wireless infrared communications. Proceedings of the IEEE, 85(2), pp.265-298, 1997.

[31] J. B. Carruther, and J. M. Kahn. Angle diversity for nondirected wireless infrared communication. IEEE Transactions on Communications, 48(6), pp.960-969, 2000.

[32] D. Tsonev, H. Chun, S. Rajbhandari, el al. A 3-Gb/s Single-LED OFDM-Based Wireless VLC Link Using a Gallium Nitride \$ \mu \{ \rm LED $\$$. IEEE Photonics Technology Letters, 26(7), pp.637-640, 2014.

[33]Z. Wang, W. D. Zhong, C. Yu, et al. Performance of dimming control scheme in visible light communication system. Optics express, 20(17), pp.18861-18868, 2012.

[34]X. You, J. Chen, H. Zheng, et al. Efficient data transmission using MPPM dimming control in indoor visible light communication. IEEE Photonics Journal, 7(4), pp.1-12, 2015.

[35] K. A. Badawi, N. A. Mohammed, M H. Aly, Exploring BER performance of a SC-LPPM based LOSVLC system with distinctive lighting, Journal of Optoelectronics and Advanced Materials, 20(5-6), pp. 290-301, 2018.

[36] N. A. Mohammed, and K. A. Badawi. Design and performance evaluation for a non-line of sight VLC dimmable system based on SCLPPM. IEEE Access, 6, pp.52393-52405, 2018. https://doi.org/10.1109/ACCESS.2018.2869878

[37] N.A. Mohammed, K. A. Badawi, A. A. Khalaf, et al. Dimming control schemes combining IEEE 802.15. 7 and SC-LPPM modulation schemes with an adaptive M-QAM OFDM for indoor LOS VLC systems. Opto-Electronics Review, pp.203-212, 2020.

https://doi.org/10.24425/opelre.2020.135259

[38] H. Johnson. Light Bulb Showdown: LED vs. $\mathrm{CFL}$ vs. Incandescent [Online]. Available: http://www.thesimpledollar.com/the-light-bulbshowdown-leds-vs-cfls-vs-incandescent-bulbswhats-the-best-deal-now-and-in-the-future/, Accessed 29 April 2015.

[39]B. Bai, Q. He, Z. Xu, et al. The color shift key modulation with non-uniform signaling for visible light communication. In 2012 1st IEEE International Conference on Communications in China Workshops (ICCC) (pp.37-42). IEEE, 2012.

[40]J. E. Gancarz, H. Elgala, and T. D. Little. Overlapping PPM for band-limited visible light communication and dimming. Journal of Solid State Lighting, 2(1), p.3, 2015.

[41] S. M. El-Garhy, H. Fayed, and M. H. Aly. Power distribution and BER in indoor VLC with PPM based modulation schemes: a comparative study. Optical and Quantum Electronics, 51(8), p.257, 2019. 